\title{
O papel da ciência no desenvolvimento sustentável
}

\author{
M. G. K. MENON
}

$\mathrm{E}$ stou honrado por ter a oportunidade de falar neste plenário ilustre em nome da comunidade científica mundial, representada pelo Conselho Internacional das Comunidades Científicas (ICSU), do qual tenho o privilégio de ser o presidente.

O avanço da ciência e da tecnologia deve ser considerado, indubitavelmente, entre os mais extraordinários empreendimentos da humanidade atualmente. $O$ mundo material que observamos ao nosso redor é uma manifestação visível disto - um resultado direto do intenso progresso científico em larga escala e da aplicação cada vez mais rápida do conhecimento e das descobertas resultantes, obtidas por meio do desenvolvimento da tecnologia.

O progresso da ciência e da tecnologia propiciou o surgimento das sociedades industriais modernas caracterizadas pela riqueza, e a expectativa crescente de que esta estará disponível a todos. Além disso, possibilitou o aumento da produçáo de alimentos e a melhora dos sistemas preventivos de saúde, o que levou a altas taxas de crescimento populacional, principalmente nos países em desenvolvimento. Estes dois aspectós, a saber, os altos padróes de consumo junto com as aspiraçóes da humanidade em continuar neste modelo de desenvolvimento, $\mathrm{e}$ as altas taxas de crescimento populacional constituem as duas matrizes da pressão sobre o ambiente.

Alguns diriam que é o avanço da ciência e da tecnologia que provocou estes problemas, com que o mundo ora se depara. Ao contrário, nossos problemas atuais advêm do modo pelo qual estes avanços foram utilizados. E não há retorno. Nossa esperança por um futuro melhor reside em desenvolvimento adicional da ciência e da tecnologia, que possa concentrar os grandes poderes que elas conferem à humanidade para delinear novos caminhos de desenvolvimento, os quais podem, e devem, ser seguros e sustentáveis do ponto de vista ambiental. Tais 
caminhos clamariam pela reduçáo do uso de recursos, particularmente de energia, para produzir os mesmos resultados. Eles ainda deveriam conduzir à eliminação da pobreza, e isto, junto com a educaçáo e outros aspectos do desenvolvimento de recursos humanos, resultariam na redução da taxa de crescimento populacional. É somente então que poderemos manter sob controle as duas forças matrizes que levam ao desequilíbrio ambiental. A melhoria do meio ambiente, a atenuação da pobreza, a redução do crescimento populacional, $\mathrm{e}$ as novas abordagens que proporcionem os bens e serviços que a sociedade necessita e aspira estáo todos inextrincavelmente ligados.

Reunimo-nos em um momento que deve ser considerado como uma importante virada na história humana para redefinir a direção dos futuros desenvolvimentos humanos, de tal forma a permitir um progresso sutentável, sobre uma base eqüitativa para toda a humanidade.

Gostaria de assegurar a esta Conferência que a comunidade científica mundial está totalmente preparada para desempenhar seu papel nessa empresa.

Temos tido consciência, durante as últimas décadas, da constante deteriorizaçáo que vem ocorrendo no meio ambiente. Inicialmente, esta consciência estava relacionada a uma deteriorização a nível local, $\mathrm{c}$ até certo ponto regional - uma deteriorização que era mais evidente na forma da poluição do ar, da água e do solo assim como no desflorestamento.

Nos últimos tempos, tem havido uma maior conscientização de atividades humanas que produzem mudanças mais insidiosas, mais globais e permanentes, e que teriam consequiências extremamente sérias para a existência humana na terra. Esta deteriorização é em grande parte intangível, manifestando-se apenas por meio de cuidadosos trabalhos científicos. Isto inclui: a perda irreversível da biodivcrsidade, redução do ozônio, aumento das concentrações gasosas relativas ao efeito estufa, levando a possíveis mudanças climáticas e ao aumento do nível do mar, perda da parte superior do solo e desertificação, poluição das zonas litorâneas e marítimas e etc .

É importante ressaltar que é o trabalho da comunidade científica desenvolvido durante várias décadas sobre estas questóes, que trouxe estes aspectos ao conhecimento da sociedade. É isto que levou a uma maior conscientização geral para que povos e governos, pela primeira vez na história, devotassem uma grande parte do seu tempo ao meio ambiente global e ao impacto das atividades humanas sobre este. É isto que foi a base para as Convençóes sobre Clima e Biodiversidade que 
foram elaboradas para que as naçóes de todo o mundo a elas aderissem; o mesmo ocorre também para o Protocolo de Montrcal sobre o Ozônio.

Assim sendo, a comunidade científica tem uma responsabilidade, que esta cumprindo, de fornecer informaçóes mais precisas acerca da presente situação do planeta Terra, particularmente no que diz respeito aos aspectos essenciais que definem o seu bem estar, e para monitorar as mudanças que vêm ocorrendo devido ao aumento crescente das atividades humanas. Para tudo isto temos agora disponíveis instrumentos poderosos tais como satélites de observaçáo terrestre, grandes navios oceanográficos, computadores para armazenamento, acesso e manipulação de enorme quantidade de dados, instrumentação sofisticada e etc.. Não é suficiente apenas monitorar mudanças. É ainda necessário modelar a natureza da mudança, reduzir incertezas e fornecer uma análise que dirá à humanidade para onde ela caminha. Todo este trabalho científico necessitará ser apoiado - pois somente ele pode fornecer o conhecimento de onde estamos, em qual direção estamos indo, quais são as prováveis conseqüências e como podemos evitar caminhos que podem ser perigosos.

Os problemas são de natureza global e trabalhar neles demanda, necessariamente, um esforço internacional. Três quintos da porção terrestre do planeta constituem-se de países em desenvolvimento, que devem, portanto, participar deste esforço.

A comunidade científica internacional está bem familiarizada com os esforços de estudar o meio ambiente na escala global. Tais esforços já tinham começado no final do século passado, e este século tem presenciado uma série de programas de pesquisa internacional que investigam as diferentes facetas do meio ambiente terrestre. O Programa Internacional Geosfera-Biosfera é o mais recente programa de pesquisa do ICSU sobre mudanças globais, o qual complementa o Programa de Pesquisa Climática Mundial, que por sua viez é um empreendimento conjunto ICSU-WMO-IOC. Juntos, eles constituem os programas de pesquisa mais ambiciosos, tal como foi reconhecido pela Assembléia Geral das Naçóes Unidas. Agora, eles estáo sendo complementados por dois importantes sistemas de observação que estão sendo criados: o Sistema Global de Observaçăo Climática e o Sistema Global de Observação Oceânica, ambos empreendimentos de co-gestáo entre organizaçóes intergovernamentais e o ICSU.

Por outro lado, a comunidade científica está consciente que o estudo científico das mudanças globais, ou mesmo, de todos os outros aspectos do meio ambiente, não representa a totalidade dos esforços necessários para produzir desenvolvimento sustentável. 
Os cientistas sabem que para isto, enquanto que a ciência e a tecnologia são importantes, a transformação da sociedade é essencial. 'Há várias maneira pelas quais podemos diminuir aspectos danosos das mudanças globais mesmo hoje em dia - e contribuir para uma significativa redução da pobreza. Isto porém náo está ocorrendo. $O$ problema reside na esfera crucial das relaçóes humanas. Os cientistas se dáo conta que, além do avanço da ciência e de suas aplicaçóes que são apropriadas para atingir o desenvolvimento sustentável, a ciência deva estabelecer parcerias com outros setores da sociedade: com a engenharia $e$ as ciências sociais, com o comércio e a indústria, com organizaçóes governamentais e intergovernamentais, e principalmente, com os setores náo-governamentais voluntários $\mathrm{e}$ independentes que atuam dirctamente na sociedade. A comunidade científica reconhece que é parte da sociedade, e que deve contribuir para as necessárias transformações sociais que podem implantar o desenvolvimento sustentável. Portanto, foi natural que o ICSU respondesse afirmativamente ao pedido do Sr. M. Strong, para fornecer apoio científico à UNCED e, com este objetivo, organizar a Conferência sobre uma Agenda da Ciência para o Meio Ambiente e Desenvolvimento no Século 21, denominada de ASCEND 21, realizada em Viena em novembro do ano passado. Isto foi fcito em colaboração com a Academia de Ciências do Tercciro Mundo, com o Consclho Internacional de Ciências Sociais e uma variedade de outras entidades não-governamentais. Os resultados desta Conferĉncia serviram como base para as preparaçóes do capítulo da Agenda 21 sobre Ciência para o Desenvolvimento Sustentável, e ambos estáo em plena harmonia entre si. Além disso, o ICSU declarou, em Viena, sua prontidão em expandir sua capacidade de preparar avaliaçóes científicas objetivas sobre questóes de desenvolvimento e meio ambiente, dentro de sua esfera de competência; para fortalecer seus programas de capacitaçáo científica nos países em desenvolvimento; e sua prontidáo em ajudar quaisquer mecanismos que sejam criados para avaliar o desempenho da Agenda 21.

É claro que a comunidade científica mundial já está trabalhando arduamente nos estudos sobre mudanças globais e clima mundial, assim como $\mathrm{em}$ vários outros aspectos relativos ao meio ambiente. Ela já estabeleu, e continuará adicionando, muitas estruturas e sistemas que relacionam o trabalho nas ciências naturais à tecnologia e outras facetas envolvidas na produção das principais transformaçóes da sociedade. Tais esforços precisam ser apoiados e fortalecidos - mais do que criar sistemas institucionais totalmente novos, com seus custos e defasagens concomitantes. A consciência científica internacional está alerta, e trabalhará para a otimizaçăo dos recursos, tanto físicos quanto morais, necessários para o estabelecimento do desenvolvimento sustentável. 
Gostaria de concluir com uma afirmação feita por Albert Einstein, um dos maiores cientistas do nosso tempo: "Preocupaçáo com o homem e seu destino deve sempre ser o interesse principal de todo esforço técnico. Nunca se esqueçam disso entre seus diagramas e equaçốs" .

M. G. K. Menon é presidente do Conselho Internacional das Comunidades Cientificas (ICSU).

Pronunciamento feito pelo autor no dia 9 de junho de 1992 para o Plenário da Unced. As principais idéias deste texto foram discutidas pelo autor no IEA com os integrantes da Area de Ciências Ambientais no dia 8 de junho de 1992.

Traduçà̃o de Edélcio Gonçalves de Souza. $O$ original em inglês encontra-se à disposição do leitor no IEÂ para eventual consulta. 